University of Windsor

Scholarship at UWindsor

2013

\title{
Towards a Model of Conscientious Corporate Brands: A Canadian Study
}

David Hutchinson Dr.

University of Windsor

Jang Singh

University of Windsor

Goran Svensson

Oslo School of Management

Tore Mysen

Oslo School of Management

Follow this and additional works at: https://scholar.uwindsor.ca/odettepub

Part of the Business Commons

\section{Recommended Citation}

Hutchinson, David Dr.; Singh, Jang; Svensson, Goran; and Mysen, Tore. (2013). Towards a Model of Conscientious Corporate Brands: A Canadian Study. Journal of Business \& Industrial Marketing, 28 (8), 687-695.

https://scholar.uwindsor.ca/odettepub/77

This Article is brought to you for free and open access by the Odette School of Business at Scholarship at UWindsor. It has been accepted for inclusion in Odette School of Business Publications by an authorized administrator of Scholarship at UWindsor. For more information, please contact scholarship@uwindsor.ca. 


\section{Towards a Model of Conscientious Corporate Brands: A Canadian Study}

Published in the Journal of Business \& Industrial Marketing, 28 (8) 2013

David Hutchinson, Assistant Professor, Marketing

Odette School of Business, University of Windsor, Canada, N9B 3P4

dhutch@uwindsor.ca ; 519.253.3000 ext 3112

Fax: 519.973.7073

Corresponding author

Jang Singh, Professor

Odette School of Business, University of Windsor, Canada

jang@uwindsor,ca ; 519.253.3000 x3141

Fax: 519.973.7073

Göran Svensson, Professor

Oslo School of Management,

P.O. Box 1195, Sentrum, 0107 Oslo, Norway

goran.svensson@hh.se

+46705228805

Tore Mysen, Associate Professor

Oslo School of Management,

P.O. Box 1195, Sentrum, 0107 Oslo, Norway

tore.mysen@mh.no

+4722596200

\section{Acknowledgements}

The authors would like to acknowledge the Purchasing Management Association of Canada (PMAC), and the Propurchaser.com of Canada for their assistance in the data collection process of this study. As well as, the acknowledgement of financial assistance from the Odette School of Business for the research and teaching innovation fund (TRIF) grant. Finally, the authors are thankful to the reviewers and editor for their time and constructive comments.

\section{BRIEF BIOGRAPHY}

David Hutchinson, Ph.D.

Odette School of Business, University of Windsor, Canada, N9B 3P4

dhutch@uwindsor.ca ; 519.253.3000 ext 3112

Field of research: Marketing: Relationship building between organizations.

Background: is an Assistant Professor of Marketing at the Odette School of Business at the University of Windsor, with research interests in the area of business to business marketing and marketing education. He had worked in the sales and marketing area, for corporations such as $3 \mathrm{M}$ Health Care. He has since completed a Ph.D. and is active in research involving simulation and gaming and customer-supplier relationship marketing

Jang Singh, Ph.D.

Odette School of Business, University of Windsor, Canada, N9B 3P4 
jang@uwindsor.ca ; 519.253.3000x3141

Dr. Jang Singh is Professor at the Odette School of Business, University of Windsor, Canada. While he has published in many areas his research focus is Business Ethics with particular emphasis on corporate codes of ethics. His research papers have been published in several scholarly journals including Journal of World Business, Journal of Business Ethics and Business and Society Review.

Göran Svensson, Professor

Oslo School of Management,

P.O. Box 1195, Sentrum, 0107 Oslo, Norway

goran.svensson@hh.se ; +46705228805

Professor at Oslo School of Management, Norway. Also, Professor at Halmstad University, Sweden and Honorary Professor at Deakin University, Australia, as well as visiting professor at University of Johannesburg, South Africa. Holds a Ph. D. at the School of Economics and Commercial Law, Göteborg University, Sweden. A committed member of the international research community as journal editor, numerous editorial boards and scholarly/research networks and associations. Author of international journal articles and international conference contributions and engaged as a book author. Published in areas such as: business ethics, leadership, logistics, marketing, sustainability, public sector management, quality management, academic journals and publishing. A background as an industrialist and entrepreneur in South America. More details at: www.nordinavia.se

Tore Mysen, Associate Professor

Oslo School of Management, P.O. Box 1195, Sentrum, 0107 Oslo, Norway

tore.mysen@mh.no;+4722596200

Field of research: Relationship building between - and within companies. International marketing.

Background: Associate Professor at Oslo School of Management, Norway. He holds a Dr. Oecon (Ph.D) at Norwegian School of Management BI. He has background as an entrepreneur and from management and board positions within telecommunication industry. His research agenda consists of various subjects within inter-firm relationships, such as: governance of foreign collaborative partners, co-ordination and cooperation, relationship management, relationship quality and relationship climate. He has published in various international journals. Furthermore, he is a member of editorial boards and is committed as track chair and session chair at conferences.

\title{
Towards a Model of Conscientious Corporate Brands: A Canadian Study
}

\author{
ABSTRACT: \\ Purpose - This paper attempts to validate a conceptual model for Conscientious Corporate Brands (CCB) \\ by exploring environmental and climate change issues together with perceptions of the internal and \\ external effectiveness of corporate codes of ethics as dimensions of CCBs.
}


Design/methodology/approach - By surveying organizations, the paper attempts to extend and validate previous research in ethical branding by proposing an additional empirically grounded conceptual model of 'the conscientious dimension' of corporate brands.

Findings - The conscientious character of a corporate brand is a multi-construct concept that may be evaluated by the components of: a) climate change, b) environmental impact, c) internal corporate codes of ethics, and d) external corporate codes of ethics as dimensions of the brand.

Research limitations/implications - The CCB model was tested on a sample of small, medium and large sized companies in Canada, which may indicate less generalizability to larger companies or in other countries and contextual settings.

Practical implications - The CCB-framework provides insights into the relationship between the natural environment, climate change and corporate codes of ethics, which organizational managers might relate to their organization.

Originality/value - This empirical study extends previous research by studying the willingness among business managers to support aspects of conscientious corporate brands (CCBs) in business-to-business relationships: when considering the impact of their brands on the natural environment and climate change, and when considering their corporate codes of ethics. Such findings imply that ethical conscientiousness is not just a rider to brand value; rather, it is an integral dimension in the manufacturer-supplier relationship.

\section{KEY WORDS:}

Canada, conscientious corporate brand, code of ethics, natural environment, climate change, business-tobusiness

\section{INTRODUCTION}

This study seeks to validate a conceptual foundation for Conscientious Corporate Brands (CCBs - Rindell et al., 2011) by investigating environmental and climate change issues together with perceptions of the internal and external effectiveness of corporate codes of ethics as dimensions of CCBs. The aim is to validate and extend previous research in ethical branding by proposing an additional empirically grounded conceptual model for 'the conscientious dimension' of a corporate brand. The research context for this paper is based upon relationships among Canadian organizations, versus the Rindell et al. (2011) Scandinavian study.

According to Rindell et al (2011), CCBs represent corporate brands and products in which the ethical concerns and values are embedded in the company's business strategy, in the value and supply chain, 
and over time in the vision and culture. The evolution over time is supported by Werther and Chandler (2005) who suggest that corporate brands are grounded with the development of society, buyer-seller relationships (Ford, 2001), and consumers' image development. Rindell and Standvik (2010) propose that over time in Conscientious Corporate Brands, corporate images should become aligned with an organization's mission, vision, and culture (Hatch and Schultz, 2001). In summary, CCBs are considered long-term, consistent, and project holistic socially responsible behaviour in an organizational brand strategy.

Three issues should be considered when discussing Conscientious Corporate Brands. First, a CCB should be considered ethical (no harm to public good), there must be co-operation along the value and supply chain, from producer to consumer (Scheuing, 1996) striving for the same ethical goals, so that all business relationships in the chain enhance rather than diminish (Håkansson and Snehota, 1995) the brand value. For example, Ben \& Jerry's brand ice cream is ethically positioned, while Nike's overseas sourcing policy created an issue (Crane, 2001). Second, strategic corporate social responsibility (CSR), a reflection of corporate programs and investment in sustainability (Wang, 2010), should be considered as it offers an insurance for global brands by positioning CSR to define the organizational mind-set (Werther and Chandler, 2005). The Gap's 'sweatshop' labour would exemplify the issues that can arise for a brand when CSR is not at the core of organizational identity. Finally, Golicic et al. (2010) argue that organizations should integrate sustainability practices throughout their supply chains because key stakeholders monitor sustainability efforts themselves, and make purchasing decisions accordingly (Golicic et al., 2010). "The process towards sustainable business must be anchored and supported by the top-level management and sometimes by the owners of companies, and it has to be a long-term commitment" (Høgevold and Svensson, 2012, p.148).In addition, the "end-of-the-pipe approach does not eliminate pollutants, but merely transforms them from one medium to another" (Eltayeb et al., 2010, p.495). As Rindell et al. (2011) posit, while these three issues appear to contribute to the development of CCBs, previous research within branding has addressed these issues holistically only to a minor extent. The current study replicates and validates the holistic examination of these issues in a Canadian setting.

Hence, ethical issues concerning buyers' sustainability practices in their supplier relationships are of particular interest in this study, and raise the following research questions: To what extent do Canadian buyers implement code of ethics provisions related to climate change and environmental impact in their supplier relationships; and, to what extent do suppliers adapt to the ethical standards as signalled by buyers. 
By focussing on Canadian buyer-supplier relationships, this study increases the insight into what extent corporate social responsibility is implemented in supply chains. Incorporating code of ethics provisions related to sustainability in company strategies directed at supplier relationships is fundamental to building brand awareness, enhancing brand image, establishing brand credibility, evoking brand feelings, and eliciting brand engagement among company customers (Keller, Apéria, and Georgson, 2008). For practitioners, this study adds support to the argument that including code of ethics provisions related to sustainability creates, or increases, brand value.

\section{LITERATURE REVIEW}

"All company names are, to some degree, corporate brands" (Kay, 2006, p.753), and can be distinct from the product brands or closely associated or part of the product brand names. For example, Canada's largest generic drug manufacturer Apotex Inc. uses the suffix "Apo" in branding many of their generic medications, as in 'APO-ACETAMINOPHEN'. In essence, conscientious corporate brands and products as defined by Rindell et al. (2011) and as used in this study incorporates four variables: ethics in the organization and supply chain and concern for climate change and environmental impact. This focussed literature review therefore addresses these four issues.

Smoking industrial chimneys have been polluting the environment since the industrial revolution. More recently, with greater global attention on the human and corporate impact on the natural environment (Solomon et al., 2007), corporate codes of ethics as instruments that address these concerns have become of greater importance in business, not only to consumers, but also to other stakeholders in the marketplace and in society. For example, organizations such as the Canadian coffee and bake retail chain Tim Hortons now recommend that members of their value chain agree to a Code of Conduct (Tim Hortons, 2010b). The Intergovernmental Panel on Climate Change's (IPCC) Fourth Assessment Report (Solomon et al., 2007) points to the urgent need for sustainable business operations. The IPCC report of 2007 (Solomon et al.) emphasizes the importance in developing sustainable business models. According to Vranceanu, (2005): "Businesses would probably improve the quality of their interactions with the public at large if the ethical dimension were to become a fully-fledged component of their management systems in general" (p.104). As developing countries rise in economic power, ethical doubts may also be increasing regarding present consumption behaviour on a global scale. It is generally believed that the use of non-renewable resources, contamination and waste residuals caused by increasing consumption patterns are hardly sustainable; therefore, the concept of ethical consumption becomes of interest to all 
stakeholders (Svensson, 2008b). Hence, there is an inter-connection of the natural environment, climate change, and corporate codes of ethics (applied both internally and in the supply chain).

Further to environmental concerns and changing consumption behaviour, one visible example of pollution caused by consumer products is packaging and the need for environmentally friendly packaging is obvious. Ecological package changes are feasible from a technological perspective and there is consumer demand for these items (Schwepker and Cornwell, 1991). Trudel and Cotte (2009) report that consumers have gone beyond positive attitudes towards sustainable produced products, and to some extent a willingness to pay more for these products; consumers are even demanding discounts from organizations producing products unethically (Creyer and Ross, 1996). Moreover, the perception of ethical behaviour by an organization, and their suppliers, can have a positive influence on a firm's image and reputation (Pretious and Love, 2006). An example of this development is the abundance of global ethically labelled brands such as Fair Trade Certified ${ }^{\mathrm{TM}}$ coffee (Neilson and Pritchard, 2007). The adherents of this movement promote paying a higher price to producers of ethical products with certain social and environmental standards (Creyer and Ross, 1997, Lim et al., 2010). This development has also influenced the demand for an ethical dimension in brand value (Nandan, 2005, De Pelsmacker et al., 2003). Rubin et al. (2008) argue that consumers in North America, who are accustomed to Nordic brands such as Volvo and Saab, are moving towards Nordic brand values.

According to Kerr, "Environmental sustainability is being embraced by more of the most competitive and successful multinational companies" (Kerr, 2007, p.668). As suggested by Hopkins (2009), if a corporation does not find sustainability, sustainability will find it. More companies now realise that it is necessary to achieve long-term sustainability in their business operations and industry (Turner and Houston, 2009). Sharma and Henriques (2005) suggest that if organizations are not proactive in regards to sustainability concerns even small stakeholders may organize through social media and demand that governments impose regulatory provisions to protect communities and the natural environment. Sustainability is also important in the case of suppliers and raw material producers, as exemplified by fair trade in the coffee industry. Sustainability and Corporate Social Responsibility (CSR) are now considered competitive imperatives (Mahler, 2007), rather than costly inconveniences. By association, a conscientious corporate brand is also a competitive imperative. Van Marrwijk (2003) reporting on worldwide research by Ernst \& Young indicate that only $11 \%$ of their sample had actually implemented a sustainability strategy. By 2007, a study by A.T. Kearney suggested $60 \%$ of organizations had adopted sustainable business strategies that strengthened or differentiated the corporate brand (Mahler, 2007). A corporate brand encompasses not only the product line, but also how it is produced, knowledge of the procurement from suppliers and producers, and physical distribution (Mulani, 2009, Carter and Rogers, 2008). Byrne (2007) suggests that a brand's image, reputation, and value may be enhanced by investment in people, the brand's ecological impact and its supply chain. 
Sustainable issues are not new; Rachel Carson (1962) visualized sustainable business models that produced no negative impacts on the environment. Later in 1987 the World Commission on Environment and Development report (Brundtland, 1987) focused on sustainability, which suggested that sustainable business models should meet present requirements and not compromise the ability of future generations to meet their own needs. Anselmsson and Johansson (2007) suggest that consumers now assume that corporate retailers are intimately aware of their corporate social responsibilities (CSR) and environmental responsibility is perhaps the most commonly used CSR dimension.

Yet, as stated by Carroll (1991), while marketing ethics has been discussed in the literature since the 1960s many questions on ethical branding remain unanswered (Fan, 2005). Ethical branding relates to moral principles that define right or wrong behavior in branding decisions (Abela, 2003) and how the brand helps "promote public good" (Fan, 2005, p. 343). Fan (2005) suggests additional research is needed on ethical branding versus unethical branding and on the relationship between a brand and society (Bhatti et al., 2011). Willmott (2003) suggests the concept 'citizen brands' as a challenge to organizations to consider the relationship between companies, consumers, and 'putting society at the heart of the company' (p.369). Crane (2001) proposes a matrix for ethical product concept evaluation (direction of ethical augmentation: negative, neutral, positive) which includes the product, marketing, corporation, and country dimensions. In a case study of Benetton, a global luxury fashion brand, Borgersonet al(2009) note that Benetton publicly communicated its ethical brand promise, "but failed to operationalize that identity throughout the organization" (p.220), which led to failure in capitalizing on the positive effects of that organizational identity. In summary, research questions appear to be unanswered from a branding perspective and the consumers' ethical concern constitutes a growing area of importance (Hall, 2007).

As observed by Carter (2000), ethical business or corporate social responsibility issues have been on the research agenda within relationship management, especially business-to-business relationships. However, ethical issues in the area of pricing, advertising, and credit practices appear to have been the focus regarding behavior and duties of the business partners (Murphy et al., 2007, Abela and Murphy, 2008). Environmental concerns in business networks are now appearing but are still understudied in the marketing literature (Manna et al., 2011).

Adams and Raisborough (2010) suggest that in contemporary markets there are various approaches to understanding ethical brands and consumer ethical consumption, which leads to difficult ethical choices 
in developing products and brands in competitive markets. Increasing concerns about the environment, associated climate change, organizational and supply chain ethics are now a reality and how organizations address these concerns will be a factor in their future competitiveness.

\section{METHOD}

\section{Research Context and Sample}

This empirical study of Canadian organizations tests a conscientious corporate brands (CCB) model proposed by Rindell et al. (2011), and derived from the literature discussed above, consisting of the following four components: a) environmental impact, b) climate change, c) internal corporate codes of ethics and d) external corporate codes of ethics.

The Canadian sample consisted of managers and executives in small to large sized organizations (revenue of \$2 million to 153 billion). The data were collected in three waves, with a determined effort to maximize participation and ensure a representative list of respondents. In the first wave, recipients of the newsletter of a national association of purchasing professionals were invited to complete an on-line survey. The association estimates that the newsletter is received by 7000 persons. However, organizations may have 2-3 recipients of the association newsletter. A second request was sent to approximately 2700 members of a group whose members are highly likely to also be members of the national association. In the third wave of data collection, the research instrument was sent to 774 named officers of Canada's largest corporations (with 101 of these returned as the named official had left the company). This group is also likely a subset of the national association. The data were therefore collected in a cascading manner to maximize the rate of return. This data collection process yielded 165 downloaded returns, 7 letters stating that the request was forwarded to the purchasing department, 8 letters indicating that it was company policy not to respond to surveys and 5 indicating that the addressee had left the company. Fifteen of the completed questionnaires were discarded as being incomplete outliers. The useable 150 questionnaires were from respondents representing a broad cross section of Canadian purchasing professionals.

Slightly more than thirty-eight percent $(38.7 \%)$ of the 150 respondents were from privately owned firms and $45.3 \%$ were from publicly owned firms. The other respondents were employed in firms owned by suppliers, manufacturers, cooperatives etc.

The number of years the organizations have worked with their current supplier ranged from one to ninety, with a mean of 13.6 years. Of the 150 respondents, 94 are males and 56 females. One hundred and 
eighteen $(78.7 \%)$ of the respondents are university educated, $10(6.7 \%)$ reported high school as their highest level of education attained, 2 (1.3\%) reported grade school and 20 (13.3\%) identified "Other" as their highest level of education. The length of employment of the respondents with their current employers ranged from six months to thirty-seven years (mean length of service was 9.4 years) and their experience in the industry ranged from six months to thirty-eight years (mean experience was 14 years).

As suggested by Campbell (1955), the survey instrument includes two items as informant competency checks. The two items ask how much the respondent knew about his/her firm's perspective of the study topics and how much the respondent knew about specific experiences with its suppliers. A total of $98.8 \%$ of the respondents indicated that they had a good amount of knowledge about their firm's perspective in regard to its suppliers and $99.4 \%$ indicated that they also had a good amount of knowledge about their firm's experiences with their suppliers. Consequently, all 150 questionnaires were used in the data analysis.

\section{Measures and Scale Items}

To test the CCB model in Canada, the questionnaire contained measurement scales (see Table1) adapted from Svensson (2008b) and from Svensson, Wood, Singh, and Callaghan (2009b). A five point Likerttype scale, anchored at 5 (strongly agree) and 1 (strongly disagree) was used for all variables.

\section{Insert Table 1 about here: Scale items by Construct}

\section{RESULTS}

\section{Measurement Model}

To test the measurement properties of the CCB model, a confirmatory factor analysis was used on the Canadian sample (Jöreskog and Sörbom, 1976, Arbuckle, 2003). Confirmatory factor analyses were run with the items and measurement model (i.e., 12 indicator variables as shown in Figure 1) using the SPSS/AMOS 18.0 software.

\section{Insert about here: Figure 1 - Four-Construct Measurement Model}


The measurement model of CCB was tested and the goodness-of-fit measures were found to be within the recommended guidelines (Hair et al., 2006). For example, the Chi-square was 143.800 with 48 degrees of freedom. This Chi-square was statistically significant $(p=0.00)$. As a result, other fit statistics

were examined. The normed Chi-square ( $\mathrm{X}^{2} / \mathrm{df}$ ) was 2.996 , while the NFI was 0.91, the IFI was 0.94, the TLI was 0.90 , the CFI was 0.94 , and RMSEA was 0.116 , all of which satisfy the recommended guidelines except for RMSEA, which is considered marginal (Hair, 1998).

\section{Assessment of Construct Validity and Reliability}

To assess the validity and reliability of the CCB-model several measures were used (see Table 2). Convergent validity is the extent to which individual items in a construct share variance between them and is measured based on the variance extracted from each construct. The variance extracted for all constructs exceeded the recommended 50 percent (Hair et al., 2006, p.745-749.)as shown in Table 2, ranging between $56-94 \%$. Reliability is also considered when evaluating constructs. The CCB-constructs exhibited composite trait reliability levels ranging between 0.80 and 0.98 , exceeding the generally accepted guideline of 0.7 (Hair et al., 2006, p.745-749.).

\section{Insert Table 2about here: Inter-Construct Correlations and Summary Statistics.}

Discriminant validity examines whether the constructs are measuring different concepts (Hair et al., 2006) and is assessed by comparing the square root of the variance extracted to the inter-construct correlations. The square root variance extracted should be larger than the corresponding inter-construct correlations and this condition was met in all cases in the measurement model (Table 2). Consequently, the CCB-model exhibited discriminant validity. Nomological validity means the relationships between constructs are consistent with theory (Figure 1). The conceptual model of conscientious corporate brand, as presented in figure 1, was first tested by Rindell et al. (2011). Later the model was validated by Lee et al. (2012), and Bogaards et al. (2012). The significant relationships among the constructs in these previous studies are confirmed in this study, thus indicating nomological validity. 
In summary, the analysis indicates that the recommended guidelines for convergent, discriminant and nomological validity, as well as construct reliability, were all met. It is therefore concluded that the measurement properties of CCB in the Canadian business-to-business relationships tested indicate satisfactory validity and reliability.

\section{CONCLUSION, RESEARCH LIMITATIONS AND SUGGESTIONS FOR FUTURE RESEARCH}

The results of this Canadian study suggest that the conscientious character of a corporate brand is a multiconstruct concept that may be evaluated and developed by considering the components of: a) climate change, b) environmental impact, c) internal corporate codes of ethics and d) external corporate codes of ethics of the organization as dimensions of the brand. Figure 2 illustrates these dimensions and how CCBs should be aligned with the company's internal and external stakeholders' image and image heritage (Rindell and Strandvik, 2010) as well as with the company's business relationships and society's development over time (Rindell et al., 2011). The findings of this study provide insights into conscientious corporate brand values in Canada, further to previous studies in Northern Europe, South Africa, and in Taiwan.

The results from this Canadian study add support to the consideration of sustainability provisions in codes of ethics in buyer-seller relationships, as proposed by Rindell et al. (2011). Moreover, considering recent, similar examinations of conscientious corporate branding within quite different country contexts, the results in this study further indicate that CCB is a consideration in companies' strategic processes. The Rindell et al. study comprises data from the largest companies in Norway, Finland and Sweden. Bogaards et al. (2012) find similar results in investigating large South African manufacturer-supplier relationships. Corresponding results within small and medium sized Taiwanese buyers and sellers are provided by Lee et al. (2012). The similar results within small, medium and large companies, buyers-sellers, manufacturer-suppliers, in Sweden, Finland, Norway, South Africa, and Canada, may indicate that ethical issues related to sustainability in companies' strategies, aiming to create or improve brand value, are increasingly incorporated.

\section{Insert Figure 2 about here: Dimensions to consider for a CCB}

The validation of the CCB-framework developed by Rindell et al. (2011) provides insights into the relationship between the natural environment, climate change and corporate codes of ethics. By considering the CCB model, 
organizations may consider reducing carbon emissions within the organization and supply chain. For example, organizations may investigate reusable packaging or containers with suppliers. Or, like Tim Hortons, organizations may work with suppliers to develop a common code of ethics (Tim Hortons, 2010a). This framework may assist organizational managers in Canada to consider key factors and relate them to their organization. The B2B survey results indicate that the $\mathrm{CCB}$ model makes an important contribution in terms of laying a conceptual foundation and providing the seed for further research. The findings imply that ethical conscientiousness is not just a rider to brand value; rather, it is a consideration in the manufacturer-supplier relationship in Canadian business relationships. The study penetrates new terrain in the field. Further, it makes a contribution to both theory and practice in the field of CCBs by validating and proposing concrete constructs and their dimensions for a CCB model. In effect the model while a description of the relationship among the four variables may also be seen as a prescription for the development of conscientious corporate brands.

Although the empirical findings of the measurement model indicate an acceptable fit, validity and reliability, there are some research limitations that need to be acknowledged. For example, in this study the CCB model was tested on a sample consisting of small, medium and large sized companies in Canada, which may indicate less applicability and generalizability to larger companies and companies in other countries or contextual settings (e.g., culture). Another limitation may be that a sample that contains a mix of companies does not cover all areas of business, nor is it equally represented across the sample. For example, it is possible that the relationship of these constructs will interact differently in specific contexts such as health care B2B situations where regulatory issues may affect the relationship. Moreover, the relatively small sample size may raise further questions on generalizability, concerns that may be mitigated by the confirmatory nature of the findings. Furthermore, the model was only tested on buyer-supplier dyad relationships, whereas other kinds of business relationships (e.g., seller-buyer dyad) may possess other measurement properties and relationships. Implicit in the limitations of this study are suggestions for future research, as studies should be designed to overcome these limitations. Nevertheless, like all survey research on a selected sample, we are confident that the CCB model is accurate for the sample of the assorted sized organizations examined.

The identified research limitations offer opportunities for further research. Such research might further develop the proposed CCB-model by varying the dimensions and constructs, or investigating connections to higher order constructs such as trust and loyalty. This approach would be informative and would advance the field significantly beyond the current paper and that of Rindell et al. (2011). Moreover, the CCB model validated in this study itself offers a seed for replication and refinement in other countries and cultures. 


\section{Table 1 - Scale Items by Construct}

\section{Climate Change}

a) We raise issues related to climate change in our relationship with this supplier.

b) This supplier raises issues related to climate change with us.

c) Environmental concerns are important in our relationship with this supplier.

\section{Environmental Impact}

a) We emphasize the recycling of materials when dealing with this supplier.

b) It is important that it be possible to re-use components provided by this supplier.

c) We request that this supplier provide documentation concerning the impact of the

products on the environment.

\section{Code of Ethics - Internal}

a) Our code of ethics/conduct influences our relationship with this supplier.

b) Our code may assist us in resolving ethical dilemmas with this supplier.

c) Our code assists us in our relationship with this supplier.

\section{Code of Ethics - External}

a) This supplier meets our ethical expectations.

b) This supplier behaves correctly according to our corporate values.

c) This supplier follows our ethical standards.

Table 2: Inter-Construct Correlations and Summary Statistics. 


\begin{tabular}{|c|c|c|c|c|}
\hline Variable & $\mathrm{CC}$ & $\mathbf{E}$ & CEI & CEE \\
\hline Climate Change & 0.88 & & & \\
\hline Environment & 0.59 & 0.75 & & \\
\hline Code of Ethics - Internal & 0.15 & 0.30 & 0.87 & \\
\hline $\begin{array}{l}\text { Code of ethics - } \\
\text { External }\end{array}$ & 0.14 & 0.22 & 0.55 & 0.97 \\
\hline Variance Extracted & $78 \%$ & $56 \%$ & $76 \%$ & $94 \%$ \\
\hline $\begin{array}{c}\text { Composite Trait } \\
\text { Reliability }\end{array}$ & 0.91 & 0.80 & 0.92 & 0.98 \\
\hline
\end{tabular}

Notes: Diagonal elements are the square root of the average variance extracted (AVE) between the constructs and their measures. The off-diagonal elements are correlations between the constructs. For discriminant validity, diagonal elements should be larger than the off-diagonal elements in the same row and column (Duarte \& Raposo, 2010, p.467). 
Figure 1 - Four-Construct Measurement Model

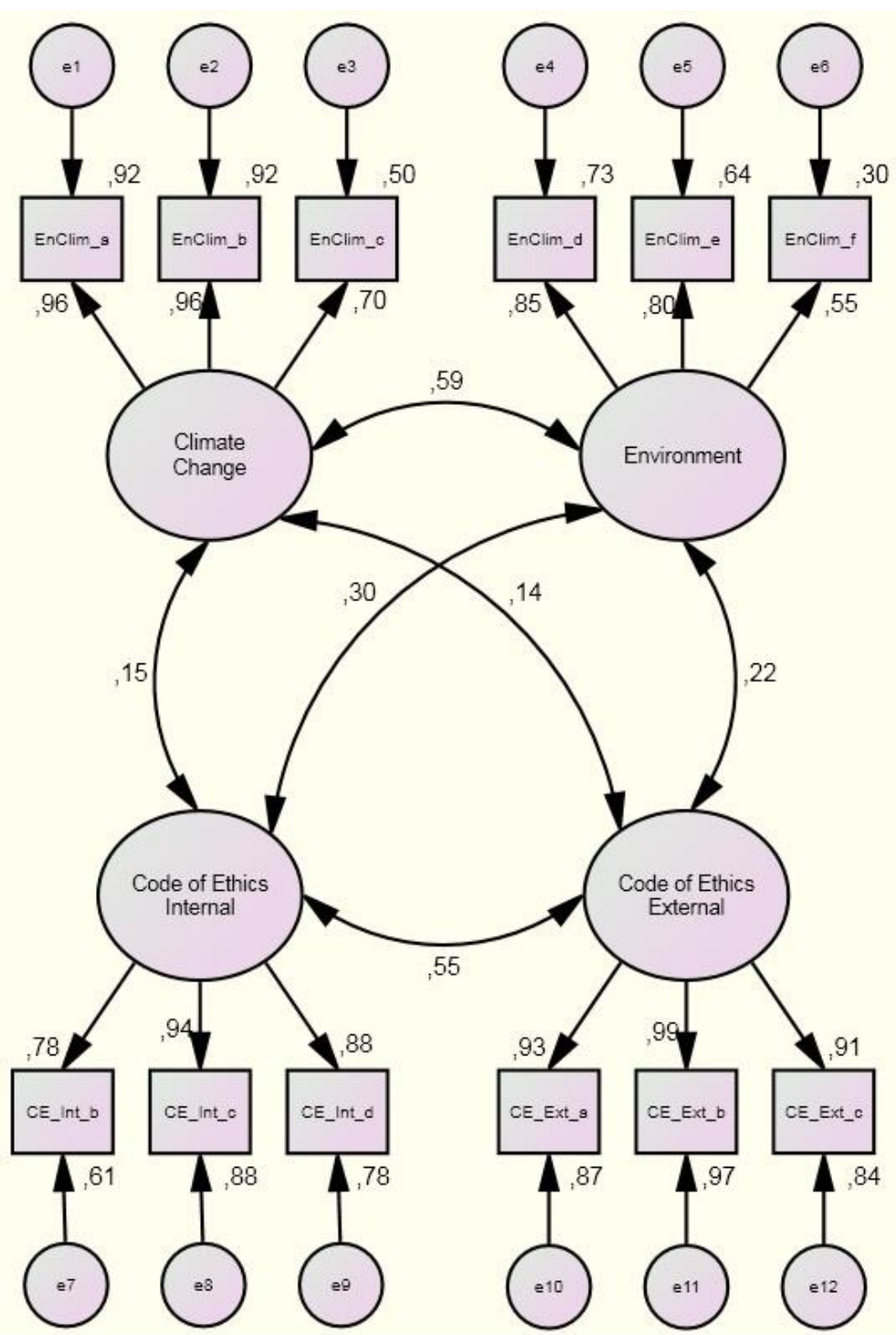


Figure 2-Dimensions to consider for a CCB

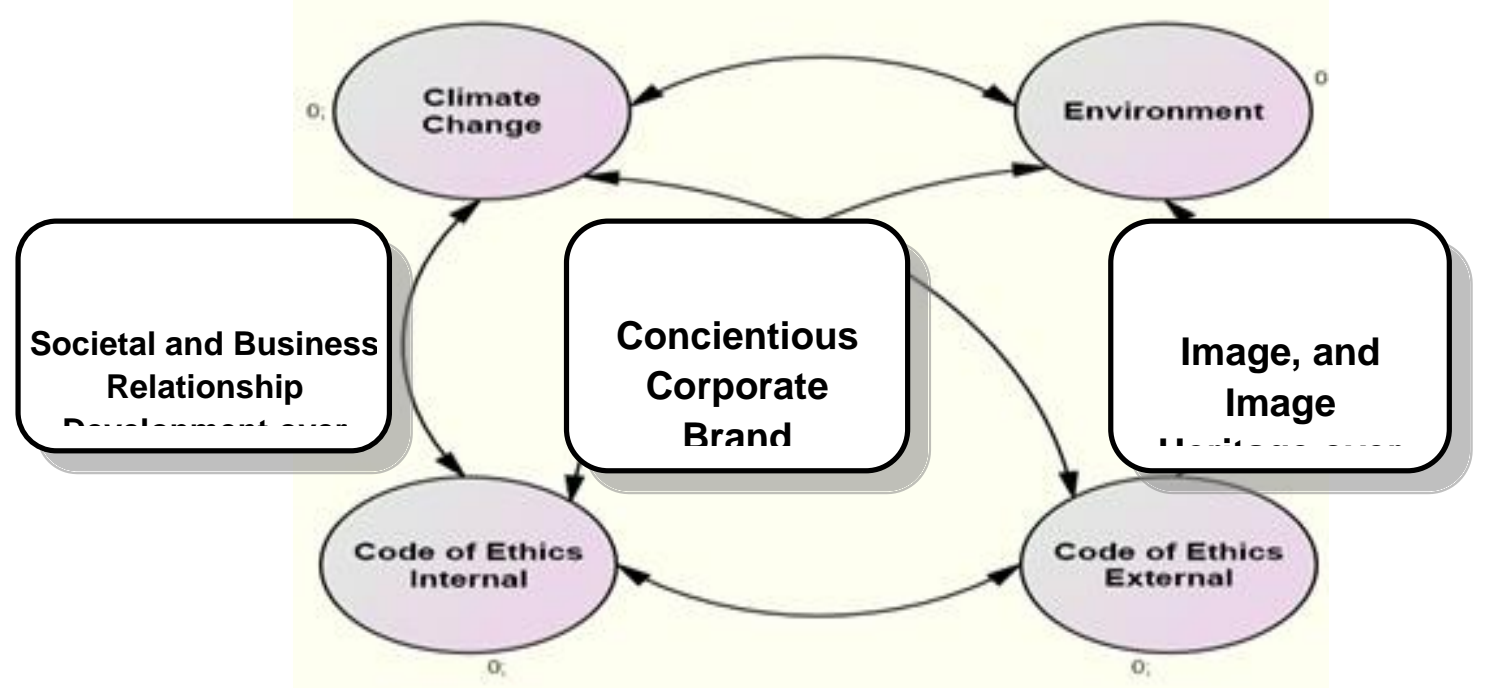

Adapted from Rindell et al.(2012) 


\section{REFERENCES}

ABELA, A. 2003. Additive versus inclusive approaches to measuring brand equity: Practical and ethical implications. Journal of Brand Management, 10, 342.

ABELA, A. V. \& MURPHY, P. E. 2008. Marketing with integrity: ethics and the service-dominant logic for marketing. Journal of the Academy of Marketing Science, 36, 39-53.

ADAMS, M. \& RAISBOROUGH, J. 2010. Making a difference: ethical consumption and the everyday. The British Journal of Sociology, 61, 256-274.

ANSELMSSON, J. \& JOHANSSON, U. 2007. Corporate social responsibility and the positioning of grocery brands: An exploratory study of retailer and manufacturer brands at point of purchase. International Journal of Retail \& Distribution Management, 35, 835-856.

ARBUCKLE, J. L. 2003. Amos, Chicago, Smallwaters.

BHATTI, I. A., PARVEEN, S. \& ARSHAD, S. 2011. Effect of perceived corporate brand on customers' attitude towards Islamic banking. International Journal of Contemporary Business Studies, 2, 5468.

BOGAARDS, M., MPINGANJIRA, M., SVENSSON, G. \& MYSEN, T. 2012. A Framework of conscientious brand - a South African study. Corporate Governance, 12(5), 675-685.

BORGERSON, J. L., SCHROEDER, J. E., ESCUDERO MAGNUSSON, M. \& MAGNUSSON, F. 2009. Corporate communication, ethics, and operational identity: a case study of Benetton. Business Ethics: A European Review, 18, 209-223.

BRUNDTLAND, G., H 1987. Our common future / World Commission on Environment and Development, Oxford, Oxford University Press.

CAMPBELL, D. 1955. The Informant in Quantitative Research. American Journal of Sociology, 60, 339342.

CARROLL, A., B 1991. The pyramid of corporate social responsibility: toward the moral management of organizational stakeholders. Business Horizons, 34, 39-48.

CARSON, R. 1962. Silent spring, Boston, Houghton Mifflin.

CARTER, C. R. 2000. Ethical issues in international buyer-supplier relationships: a dyadic examination. Journal of Operations Management, 18, 191-208. 
CARTER, R., C \& ROGERS, D., S 2008. A framework of sustainable supply chain management: moving toward new theory. International Journal of Physical Distribution \& Logistics Management, 38, 360-387.

CRANE, A. 2001. Unpacking the Ethical Product. Journal of Business Ethics, 30, 361-373.

CREYER, E. H. \& ROSS, W. T. 1996. The impact of corporate behavior on perceived product value. Marketing Letters, 7, 173.

CREYER, E. H. \& ROSS, W. T. 1997. The influence of firm behavior on purchase intention: do consumers really care about business ethics? Journal of Consumer Marketing, 14, 421-432.

DE PELSMACKER, P., DRIESEN, L. \& RAYP, G. 2003. Are fair trade labels good business? Ethics and coffee buying intentions. Ghent: Working Paper. Ghent University, Faculty of Economics and Business Adminstration.

DUARTE, P. A. O. \& RAPOSO, M. L. B. 2010. A PLS Model to Study Brand Preference An Applicxation to the Mobile Phone Market. In: VINZI, V. E. (ed.) Handbook of partial Least Squares: Concepts, Methods, and Applications. New York: Springer.

ELTAYEB, T. K., ZAILANI, S. \& RAMAYAH, T. 2010. Green supply chain initiatives among certified companies in Malaysia and environmental sustainability: Investigating the outcomes. Resources, Conservation and Recycling, 55, 495.

FAN, Y. 2005. Ethical branding and corporate reputation. Corporate Communications: An International Journal, 10, 341-350.

FORD, D. 2001. The Development of Buyer-Seller Relationships in Industrial Markets. European Journal of Marketing, 14, 339-352.

GOLICIC, S., BOERSTLER, C. \& ELLRAM, L. 2010. 'Greening' the Transportation in Your Supply Chain. MIT Sloan Management Review, 51, 47.

HAIR, J. F., ANDERSON, R. E., TATHAM, R. L., \& BLACK, W. C. (1998). Multivariate Data Analysis (5th ed.). Upper Saddle River, NJ: Prentice Hall.

HAIR, J. F., BLACK, W., BABIN, B., ANDERSON, R. \& TATHAM, R. 2006. Multivariate Data Analysis Upper Saddle River, N.J., Pearson Prentice Hall.

HÅKANSSON, H. \& SNEHOTA, I. 1995. The Burden of Relationships or Who's Next. 11th IMP Conference. Manchester.

HALL, J. 2007. The ethical opportunity. Journal of Brand Management.

HATCH, M., J \& SCHULTZ, M. 2001. Are the Strategic Stars Aligned for Your Corporate Brand. Harvard Business Review, February. 
HØGEVOLD, N. M. \& SVENSSON, G. 2012. A business sustainability model: a European case study. Journal of Business \& Industrial Marketing, 27, 142-151.

HOPKINS, M.S.2009. 8 reasons sustainability will change management(that you never thought of). MIT Sloan Management Review, 51, 26-30.

JÖRESKOG, K., G \& SÖRBOM, D. 1976. LISREL III: Estimation of linear structural equations systems by maximum likelihood methods, Chicago, Illinois, National Educational Resources, Inc.

KAY, M.J. 2006, "Strong brands and corporate brands", European Journal of Marketing, 40 nos 7/8, pp. 742-60.

KELLER, K.L., APÉRIA, T. \& GEORGSON, M. 2008.Strategic Brand Management. A European Perspective, Pearson Education, Essex, England.

KERR, J. E. 2007. Environmental sustainability is being embraced by more of the most competitive and successful multinational companies. Cardozo law Review. De Novo, 29, 623-669.

LEE, T.-R., SVENSSON, G. \& MYSEN, T. 2012. International Journal of Business and Globalization, $8(2), 256-267$.

LIM, J. M., AROKIASAMY, L. \& MOORTHY, M. K. 2010. Global Brands Conceptualization: A Perspective from the Malaysian Consumers. American Journal of Scientific Research, 36-51.

MAHLER, D. 2007. The sustainable supply chain. Supply Chain Management Review, Nov., 59-60.

MANNA, D. P., MARCO, G. P., KHALIL, B. \& MEIER, S. 2011. Sustainable Markets: Case Study Of Toyota Motor Sales, U.S.A., Inc. Journal of Business Case Studies, 7, 63.

MULANI, N. 2009. Sustainability: Your role as a supply chain leader. Logistics Management, May.

MURPHY, P., E, LACNIAK, G., R \& WOOD, G. 2007. An ethical basis for relationship marketing: a virtue ethics perspective. European Journal of Marketing, 41, 37-57.

NANDAN, S. 2005. An exploration of the brand identity-brand image linkage: A communications perspective. Journal of Brand Management, 12, 264.

NEILSON, J. \& PRITCHARD, B. 2007. Green Coffee? The Contradictions of Global Sustainability Initiatives from an Indian Perspective. Development Policy Review, 25, 311.

PRETIOUS, M. \& LOVE, M. 2006. Sourcing ethics and the global market: The case of the UK retail clothing sector. International Journal of Retail \& Distribution Management, 34, 892-903.

RINDELL, A. \& STRANDVIK, T. 2010. Corporate brand evolution - Corporate brand images evolving in consumers' everyday life. European Business Review, 22. 
RINDELL, A., SVENSSON, G., MYSEN, T., BILLSTROM, A. \& WILEN, K. 2011. Towards a Conceptual Foundation of 'Conscientious Corporate Brands'. Journal of Brand Management, Forth Coming, 709-719.

RUBIN, J., SCHULTZ, M. \& HATCH, M. J. 2008. Coming to America: Can Nordic brand values engage American stakeholders? Journal of Brand Management, 16, 30-39.

SCHEUING, E., E 1996. Sourcing Services. In: EDVARDSSON, B. \& MODELL, S. (eds.) Service Management. Göteborg: Nerenius\&Santerus förlag.

SCHWEPKER, C. H. \& CORNWELL, T. B. 1991. An Examination of Ecologically Concerned Consumers and Their Intention to Purchase Ecologically Packaged Products. Journal of Public Policy \& Marketing, 10, 77-101.

SHARMA, S. \& HENRIQUES, I. 2005. Stakeholder influences on sustainability practices in the Canadian forest products industry. Strategic Management Journal, 26, 159.

SVENSSON, G. 2008b. Anti-Climate Change Management (ACCM) - 'Business-as-Usual' or 'Out-ofthe-Box'? Management Decision, 46, 92-105.

SVENSSON, G., WOOD, G., SINGH, J. \& CALLAGHAN, M. 2009b. A Cross-Cultural Construct of the Ethos of Corporate Codes of Ethics (ECCE): Australia, Canada and Sweden. Business Ethics: A European Review, 18, 253-267.

TIM HORTONS. 2010a. The 2010 Sustainability and Responsibility Report [Online]. Available: http://sustainabilityreport.timhortons.com/ [Accessed April 2011.

TRUDEL, R. \& COTTE, J. 2009. Does it pay to be good? MIT Sloan Management Review, 50.

TURNER, M. \& HOUSTON, P. 2009. Going green? start with sourcing. Supply Chain Management Review, March 13, 14.

VAN MARREWIJK, M. 2003. Concepts and Definitions of CSR and Corporate Sustainability: Between Agency and Communion. Journal of Business Ethics, 44, 95.

VRANCEANU, R. 2005. The ethical dimension of economic choices. Business Ethics: A European Review, 14, 94.

WANG, H.-M. D. 2010. Corporate social performance and financial-based brand equity Journal of Product \& Brand Management, , 19, 335--345.

WERTHER, W., B, JR \& CHANDLER, D. 2005. Strategic corporate social responsibility as global brand insurance Business Horizons, 48, 317-324.

WILLMOTT, M. 2003. Citizen brands: Corporate citizenship, trust and branding. Journal of Brand Management, 10, 362. 